\title{
Predictors of Work-Related Musculoskeletal Disorders among Commercial Minibus Drivers in Accra Metropolis, Ghana
}

\author{
J. K. Abledu, ${ }^{1}$ E. B. Offei, ${ }^{1}$ and G. K. Abledu ${ }^{2}$ \\ ${ }^{1}$ School of Veterinary Medicine, University of Ghana, Accra, Ghana \\ ${ }^{2}$ Faculty of Applied Science and Technology, Koforidua Polytechnic, Koforidua, Ghana \\ Correspondence should be addressed to J. K. Abledu; jkabledu@gmail.com
}

Received 28 June 2014; Accepted 11 August 2014; Published 21 August 2014

Academic Editor: Jeanine M. Buchanich

Copyright (C) 2014 J. K. Abledu et al. This is an open access article distributed under the Creative Commons Attribution License, which permits unrestricted use, distribution, and reproduction in any medium, provided the original work is properly cited.

\begin{abstract}
Background. The objective of this study is to determine the prevalence and predictors of work-related musculoskeletal disorders (WMSDs) among a sample of commercial minibus drivers in the Accra Metropolis of Ghana. Methods. The participating drivers $(n=148)$ were recruited from various lorry terminals and assessed by using a semistructured questionnaire that included the Nordic Musculoskeletal Questionnaire (NMQ). Results. Of the 148 drivers, 116 (78.4\%) reported having WMSDs during the previous 12 months. The prevalence of the various WMSD domains was low back pain (58.8\%), neck pain (25\%), upper back pain (22.3\%), shoulder pain (18.2\%), knee pain (14.9\%), ankle pain (9.5\%), wrist pain (7.4\%), elbow pain (4.7\%), and hip/thigh pain (2.7\%). Multiple logistic regression analysis adjusted for possible confounders showed that less physical activity $(\mathrm{OR}=4.9 ; 95 \% \mathrm{CI}=1.5-$ $16.5 ; P=0.010)$, driving more than 12 hours per day $(\mathrm{OR}=2.9 ; 95 \% \mathrm{CI}=1.1-7.8 ; P=0.037)$, and driving at least 5 days per week $(\mathrm{OR}=3.7 ; 95 \% \mathrm{CI}=1.4-9.4 ; P=0.007)$ were significantly associated with WMSDs among this cohort of drivers. Conclusion. These modifiable factors may be targets for preventive strategies to reduce the incidence of WMSDs among occupational minibus drivers in Ghana.
\end{abstract}

\section{Introduction}

Musculoskeletal disorders (MSDs) include a wide range of musculoskeletal diseases and syndromes, which are usually associated with pain and discomfort. Work-related musculoskeletal disorders (WMSDs) are defined as impairments of the musculoskeletal system (including nerves and blood vessels) caused or aggravated primarily by work itself or by the environment in which work is performed [1]. They occur predominantly in the back, neck, upper extremities, and in some cases, lower extremities, causing significant pain and discomfort with disability and hospitalization (in severe cases). Data show that worldwide, WMSDs account for $42 \%-58 \%$ of all work-related illnesses [2,3] and $40 \%$ of all work-related health costs [2]. WMSDs are a serious public health problem given the high cost to the injured worker, his or her family, employers, and society to a large extent. The aetiology of WMSDs is multifactorial. The risk factors include awkward posture, manual handling, heavy lifting, strenuous task, and repetitive actions, while demographics, workload, and psychosocial factors are known to influence the development and progression of these disorders [2]. Environmental factors (such as temperature, noise, and light complaints) have also been cited as important risk factors of WMSDs [3].

Driving as a profession involves routine muscular effort (e.g., steering), awkward sitting postures, and exposure to whole-body vibration. Commercial minibus drivers are further exposed to biomechanically strenuous activities (such as manual load handling and lifting, bending, and twisting.) and pollution (air and noise) from the macroenvironment. Thus, the work tasks and environment put drivers at risk for WMSDs. The prevalence of WMSDs among drivers has been shown to be high and varies between $53 \%$ and $91 \%$ in different parts of the world [4-16]. Significant risk factors that have been empirically linked with WMSDs among drivers include seat discomfort $[5,12]$, exposure to whole-body vibration $[17,18]$, long driving time [11, 16], nonneutral postures [19], heavy lifting [17], manual materials handling $[5,18]$, and psychosocial factors $[12,14,16]$. 
The prevalence and risk factors of WMSDs among drivers would vary between countries due to differences in racial background, geographical location, ethnicity and socio-demographics. Although considerable epidemiological studies have explored and reported on musculoskeletal disorders among occupational drivers, few studies have been conducted in Africa and almost none in Ghana to date. An earlier report by our group [16] found a 70.5\% prevalence rate of WMSDs among taxi drivers in Accra Metropolis, hence the need to replicate this study among commercial minibus drivers in the same setting. The present study seeks to determine the 12-month prevalence, body distribution, and predictors of WMSDs among a sample of occupational minibus drivers in Accra Metropolis, Ghana.

\section{Methods}

2.1. Participants. This epidemiological cross-sectional survey was conducted among 200 commercial minibus drivers (all males) at various lorry terminals in the Accra Metropolis. Eligibility for participants was as follows: being commercial minibus driver, aging 18 years or older with at least one year experience at the current job, and having no history of traumatic road or work accidents.

2.2. Data Collection. A previously validated semistructured questionnaire was administered at interview to each participant while waiting at the lorry terminals. Participation in the study was voluntary and informed consent was obtained from each participant. The three-part questionnaire, which included the standardized Nordic Musculoskeletal Questionnaire (NMQ), was used to determine participants' sociodemographic variables such as age, marital status, religion, education, alcohol consumption, smoking status, and level of physical exercise. Participants who could neither read nor write English were assessed using a validated and standardized translation of the questionnaire (in the local Ghanaian language). Alcohol consumption was defined as the intake of at least one bottle of an alcoholic beverage per week. Physical activity was defined as any activity causing slight-tomoderate increase in breathing or heart rate for at least 30 minutes. A participant who smoked at least one cigarette a day was classified as a smoker.

The questionnaire also assessed occupational factors such as car ownership and driving time profile (years of driving, total driving hours per day, and number of days per week of driving) and psychosocial factors such as self-perceived job stress and job satisfaction of the participants.

2.3. Nordic Musculoskeletal Questionnaire (NMQ). Musculoskeletal discomfort was assessed by the NMQ [20], which is a useful tool for collection of data on self-reported musculoskeletal discomfort and sickness absence. The NMQ is a validated [20-22] tool consisting of a general questionnaire for analysis of the point prevalence (7 days), period prevalence (12 months), and severity or disability (effect on normal activities over the last 12 months) of musculoskeletal trouble in different body areas such as neck, shoulders, elbows, wrists/hands, upper back, lower back, hips/thighs, knees, and ankles/feet. The present study assessed the period prevalence of MSDs. The NMQ was chosen because it is standardized, widely accepted, easy to administer, and cost efficient.

2.4. Statistical Analysis. Data were categorized and analyzed with Statistical Package for Social Sciences (SPSS) for Windows, version 20. (IBM Corporation, USA). First, univariate logistic regression was used to obtain estimates of the prevalence odds ratio (POR) of independent factors associated with MSDs. Significant variables were entered simultaneously into a multiple logistic regression model to obtain estimates of the adjusted POR. In all statistical analyses, a value of $P<0.05$ was considered significant.

\section{Results}

3.1. Response Rate and Sociodemographic Characteristics of the Respondents. Out of the total 200 drivers that were contacted, 36 declined participation while 16 terminated participation when passengers arrived, leaving 148 complete questionnaires for final analysis. Participants' sociodemographic characteristics are presented in Table 1. The mean age of the participants was $33.0 \pm 10.6$ years (range: $20-54$ years). A majority of the participants were married (75.6\%), Christians (79.1\%), primary and junior high school leavers (54.7\%), and employee-drivers (82.4\%). The mean number of years of driving was $5.0 \pm 3.2$ years while the average duration of driving per day and per week was $12.4 \pm 2.2$ hours and $4.9 \pm 0.7$ days, respectively (not shown in the table). Many (74.3\%) of the participants perceived their job as stressful while $61(43.9 \%)$ of them were dissatisfied with their current job. More than half (56.1\%) of them took alcoholic beverages, $23 \%$ smoked cigarettes, while $14.2 \%$ were engaged in some form of sports/physical activities.

3.2. Prevalence and Pattern of WMSDs. The results indicate that a total of 116 (78.4\%) drivers suffered musculoskeletal discomfort in at least one body region during the previous 12 months. The prevalence of the various WMSD domains was low back pain (58.8\%), neck pain (25\%), upper back pain (22.3\%), shoulder pain (18.2\%), knee pain (14.9\%), ankle pain (9.5\%), wrist pain $(7.4 \%)$, elbow pain $(4.7 \%)$, and hip/thigh pain $(2.7 \%)$ pain.

3.3. Prevalence Odds Ratios of Factors Associated with WMSDs among the Participants. Factors associated with WMSDs are recorded in Table 2 . Less physical activity ( $O R=3.6 ; 95 \%$ $\mathrm{CI}=1.4-9.3 ; P<0.008$ ), religion (non-Christians) (OR $=2.5 ; 95 \% \mathrm{CI}=1.0-6.0 ; P=0.039)$ driving more than 12 hours/day $(\mathrm{OR}=2.9 ; 95 \% \mathrm{CI}=1.2-6.8 ; P=0.016)$, driving more than 5 days/week $(\mathrm{OR}=3.7 ; 95 \% \mathrm{CI}=1.7-$ $8.5 ; P=0.002)$, self-perceived job stress ( $\mathrm{OR}=3.6 ; 95 \%$ $\mathrm{CI}=1.6-8.2 ; P=0.003$ ), and dissatisfaction with job (OR $=4.5 ; 95 \% \mathrm{CI}=1.7-11.7 ; P=0.002$ ) were the significant variables associated with MSDs in the univariate analysis. After adjusting for all significant variables in multivariate analysis, the significantfactors associated with WMSDs were 
TABLE 1: Sociodemographic characteristics of participants $(n=$ 148).

\begin{tabular}{|c|c|c|}
\hline Characteristic & $n$ & $\%$ \\
\hline \multicolumn{3}{|l|}{ Age (years) } \\
\hline$<40$ & 79 & 53.4 \\
\hline $40-50$ & 42 & 32.4 \\
\hline$>50$ & 27 & 18.2 \\
\hline \multicolumn{3}{|l|}{ Marital status } \\
\hline Married & 112 & 75.6 \\
\hline Single & 36 & 24.3 \\
\hline \multicolumn{3}{|l|}{ Education } \\
\hline Primary/Junior high school & 79 & 53.4 \\
\hline Senior high school and equivalent & 69 & 46.6 \\
\hline \multicolumn{3}{|l|}{ Religion } \\
\hline Christian & 117 & 79.1 \\
\hline Moslem & 28 & 18.9 \\
\hline African Tradition & 3 & 2.0 \\
\hline \multicolumn{3}{|l|}{ Type of driver } \\
\hline Owner & 26 & 17.6 \\
\hline Employee & 122 & 82.4 \\
\hline \multicolumn{3}{|l|}{ Perceived job stress } \\
\hline None & 38 & 25.7 \\
\hline Yes & 110 & 74.3 \\
\hline \multicolumn{3}{|l|}{ Job satisfaction } \\
\hline Satisfied & 83 & 56.1 \\
\hline Dissatisfied & 65 & 43.9 \\
\hline \multicolumn{3}{|l|}{ Alcohol } \\
\hline Yes & 83 & 56.1 \\
\hline No & 65 & 43.9 \\
\hline \multicolumn{3}{|l|}{ Smoking } \\
\hline Yes & 34 & 23.0 \\
\hline No & 114 & 77.0 \\
\hline \multicolumn{3}{|l|}{ Regular physical activities } \\
\hline Yes & 23 & 15.5 \\
\hline No & 125 & 84.5 \\
\hline
\end{tabular}

Data are presented as frequencies and percentages. Total percentages may not be exactly $100 \%$ due to approximations.

less of physical activities, driving more than 12 hours/day, and driving more than 5 days per week (Table 2).

\section{Discussion}

This study supports the finding of our previous study [16] and those of other researchers [4-16] that WMSDs are highly prevalent among drivers. Whereas the prevalence of WMSDs $(78.4 \%)$ in this study falls within the 53\%-91\% prevalence range in the worldwide database for drivers, it is lower than the $91 \%$ rate reported among stage rally drivers [15] and $81 \%$ among truck drivers [5] in Europe. It is also lower than data from Nigeria [23] (i.e., 89.3\%), but higher than $70.5 \%$ found among taxi drivers from the same setting with similar sociocultural characteristics [16]. A further observation of $58.8 \%$ rate of low back pain (the predominant musculoskeletal symptom in this study) is close to the $60 \%$ prevalence rate among truck drivers in the United Kingdom [5] and $60.4 \%$ among commercial vehicle drivers in Malaysia [14] but lower than $64.8 \%$ [23] and 73.5\% [24] prevalence rates reported among occupational drivers in Nigeria. It is however higher than $34.3 \%$ in the previous study among taxi drivers [16]. These variations could, in part, be due to differences in methodology, sample size, population (race and ethnicity), and comorbidities.

From this study, prolonged driving duration (i.e., $>12$ hour/day and $\geq 5$ days/week) was significantly associated with increased odds of WMSDs among the drivers. Prolonged sitting (static posture) or muscular inactivity can exert tension (load) on the musculoskeletal structures, thus leading to musculoskeletal discomfort. A relationship between longer duration of driving and musculoskeletal discomfort is supported by several studies [9-11, 16].

Religion, self-perceived job stress, and dissatisfaction of job, all of which were independently associated with WMSDs in this study, lost their respective associations after adjusting for driving duration. The observed association between religion and WMSDs in this study could be attributed to selection bias. Psychosocial factors such as self-perceived job stress and dissatisfaction of job can lead to psychosocial stress. The exact mechanism underlying the relationship between workrelated psychosocial stressing factors and WMSDs is unclear; however, it is hypothesized that psychosocial stressors interact via complex neurogenic and neuroendocrine pathways to cause muscle tension, spinal cord strain, and fatigue that could predispose drivers to traumatic injury [12]. Burnout and musculoskeletal pain are related, but the strength of the associations varies according to gender and occupation [25]. An association between psychosocial stressors (selfperceived job stress, dissatisfaction of job, and poor mental health) and WMSDs is supported by other studies among drivers $[10,11,16]$.

Lack of physical activity was associated with increased odds of WMSDs among the participants in this study even after adjusting for possible confounders, suggesting that physical activity may be important in reducing WMSDs of drivers. Although there is evidence that physical activity enhances health $[26,27]$, literature on the relationship between physical activity and WMSDs in working populations is still inconsistent. While some studies $[28,29]$ have indicated favourable relation between the frequency of leisure time sports activity and WMSDs, others $[26,30]$ found no association between the duo while some [31] reported adverse effects of sports activities on WMSDs. This relationship has to be studied further.

Contrary to previous studies $[9,10,12,23]$, the present study found no statistically significant association between musculoskeletal discomfort and other variables such as age, number of years of driving, alcohol drinking, smoking, or ownership of vehicle. Compared with taxi drivers in the same setting [16], it seems that occupational drivers vary in terms of prevalence and predisposing factors of WMSDs. The relatively higher prevalence of WMSDs among minibus drivers in this study could be attributed to the generally bad conditions of these vehicles in the Accra Metropolis. Given 
TABLE 2: Factors associated with MSDs among the participants $(n=148)$.

\begin{tabular}{|c|c|c|c|c|c|}
\hline Characteristic & $n / N^{\ddagger}$ & OR $(95 \% \mathrm{CI})$ & $P$ value & $\mathrm{aOR}(95 \% \mathrm{CI})$ & $P$ value \\
\hline \multicolumn{6}{|l|}{ Age (years) } \\
\hline$<40$ & $67 / 79$ & 1 & & & \\
\hline $40-50$ & $30 / 42$ & $0.5(0.2-1.2)$ & 0.121 & & \\
\hline$>50$ & $19 / 27$ & $0.9(0.3-2.8)$ & 0.900 & & \\
\hline \multicolumn{6}{|l|}{ Marital status } \\
\hline Married & $92 / 112$ & 1 & & & \\
\hline Single & $24 / 36$ & $0.4(0.2-1.0)$ & 0.053 & & \\
\hline \multicolumn{6}{|l|}{ Education } \\
\hline Primary/junior high school & $61 / 79$ & 1 & & & \\
\hline Senior high school equivalent & $55 / 69$ & $1.2(0.5-2.5)$ & 0.713 & & \\
\hline \multicolumn{6}{|l|}{ Religion } \\
\hline Christian & $96 / 117$ & 1 & & 1 & \\
\hline Muslim* & $21 / 31$ & $2.5(1.0-6.0)$ & 0.039 & $2.2(0.7-6.3)$ & 0.170 \\
\hline \multicolumn{6}{|l|}{ Alcohol } \\
\hline No & $48 / 65$ & 1 & & & \\
\hline Yes & $68 / 83$ & $1.6(0.7-3.5)$ & 0.238 & & \\
\hline \multicolumn{6}{|l|}{ Smoking } \\
\hline No & $27 / 34$ & 1 & & & \\
\hline Yes & $89 / 114$ & $0.9(0.4-2.4)$ & 0.868 & & \\
\hline \multicolumn{6}{|l|}{ Sports activities } \\
\hline Yes & $13 / 23$ & 1 & & 1 & \\
\hline No & $103 / 125$ & $3.6(1.4-9.3)$ & 0.008 & $4.7(1.4-15.8)$ & 0.011 \\
\hline \multicolumn{6}{|l|}{ Type of driver } \\
\hline Owner & $22 / 26$ & 1 & & & \\
\hline Employee & $94 / 122$ & $0.6(0.2-1.9)$ & 0.398 & & \\
\hline \multicolumn{6}{|l|}{ Driving duration (years) } \\
\hline$<5$ & $34 / 48$ & 1 & & & \\
\hline $5-10$ & $46 / 59$ & $1.8(0.6-5.2)$ & 0.263 & & \\
\hline$>10$ & $36 / 43$ & $1.5(0.5-4.0)$ & 0.471 & & \\
\hline \multicolumn{6}{|l|}{ Driving time per day (hours) } \\
\hline$\leq 12$ & $20 / 32$ & 1 & & 1 & \\
\hline$>12$ & $96 / 116$ & $2.9(1.2-6.8)$ & 0.016 & $2.8(1.0-7.5)$ & 0.046 \\
\hline \multicolumn{6}{|l|}{ Driving time per week (days) } \\
\hline$<5$ & $22 / 44$ & 1 & & 1 & \\
\hline $5-7$ & $89 / 104$ & $3.7(1.7-8.5)$ & 0.002 & $4.0(1.5-10.2)$ & 0.004 \\
\hline \multicolumn{6}{|l|}{ Perceived job stress } \\
\hline None & $23 / 38$ & 1 & 1 & 1 & \\
\hline Yes & $93 / 110$ & $3.6(1.6-8.2)$ & 0.003 & $2.8(0.9-8.2)$ & 0.066 \\
\hline \multicolumn{6}{|l|}{ Job satisfaction } \\
\hline Satisfied & $55 / 83$ & 1 & & 1 & \\
\hline Dissatisfied & $61 / 65$ & $4.5(1.7-11.7)$ & 0.002 & $3.0(1.0-9.5)$ & 0.058 \\
\hline
\end{tabular}

${ }^{{ } n / N}$ : Number of subjects with MSDs/number of subjects in each category. ${ }^{*}$ Muslims and other religions combined due to very low frequency of the latter. OR: odds ratio; aOR: adjusted odds ratio; CI: confidence interval.

the differences in the vehicle and work tasks between taxi drivers and minibus drivers it is likely that the exposure to risk factors would vary between these drivers.

\section{Conclusion}

The 12-month prevalence of WMSDs among commercial minibus drivers in Accra Metropolis is high (i.e., 78.4\%). WMSDs in this population were significantly associated with less physical activity and longer driving duration. These modifiable factors may be targets for preventive strategies to reduce the incidence of MSDs among occupational minibus drivers in Ghana. Further studies are required.

\section{Conflict of Interests}

There is no conflict of interest regarding this paper. 


\section{Acknowledgments}

The authors gratefully thank all the participants and research assistants.

\section{References}

[1] I. L. Nunes, "FAST ERGO-X: a tool for ergonomic auditing and work-related musculoskeletal disorders prevention," Work, vol. 34, no. 2, pp. 133-148, 2009.

[2] J. Abledu and G. Abledu, "Multiple logistic regression analysis of predictors of musculoskeletal disorders and disability among bank workers in Kumasi, Ghana," Journal of Ergonomics, vol. 2, article 111, 2012.

[3] N. Magnavita, M. Elovainio, I. de Nardis, T. Heponiemi, and A. Bergamaschi, "Environmental discomfort and musculoskeletal disorders," Occupational Medicine, vol. 61, no. 3, pp. 196-201, 2011.

[4] N. Gkikas, Automotive Ergonomics: Driver-Vehicle Interaction, CRC Press, 2012.

[5] M. J. M. Robb and N. J. Mansfield, "Self-reported musculoskeletal problems amongst professional truck drivers," Ergonomics, vol. 50, no. 6, pp. 814-827, 2007.

[6] M. Massaccesi, A. Pagnotta, A. Soccetti, M. Masali, C. Masiero, and F. Greco, "Investigation of work-related disorders in truck drivers using RULA method," Applied Ergonomics, vol. 34, no. 4, pp. 303-307, 2003.

[7] J. Hoy, N. Mubarak, S. Nelson et al., "Whole body vibration and posture as risk factors for low back pain among forklift truck drivers," Journal of Sound and Vibration, vol. 284, no. 3-5, pp. 933-946, 2005.

[8] G. P. Y. Szeto and P. Lam, "Work-related musculoskeletal disorders in urban bus drivers of Hong Kong," Journal of Occupational Rehabilitation, vol. 17, no. 2, pp. 181-198, 2007.

[9] R. K. Raanaas and D. Anderson, "A questionnaire survey of Norwegian taxi drivers' musculoskeletal health, and work-related risk factors," International Journal of Industrial Ergonomics, vol. 38, no. 3-4, pp. 280-290, 2008.

[10] J.-C. Chen, W.-R. Chang, W. Chang et al., "Occupational factors associated with low back pain in urban taxi drivers," Occupational Medicine, vol. 55, no. 7, pp. 535-540, 2005.

[11] J.-C. Chen, J. T. Dennerlein, T.-S. Shih et al., "Knee pain and driving duration: a secondary analysis of the Taxi Drivers' Health Study," The American Journal of Public Health, vol. 94, no. 4, pp. 575-581, 2004.

[12] D. Alperovitch-Najenson, Y. Santo, Y. Masharawi, M. KatzLeurer, D. Ushvaev, and L. Kalichman, "Low back pain among professional bus drivers: ergonomic and occupationalpsychosocial risk factors," Israel Medical Association Journal, vol. 12, no. 1, pp. 26-31, 2010.

[13] J. M. Porter and D. E. Gyi, "The prevalence of musculoskeletal troubles among car drivers," Occupational Medicine, vol. 52, no. 1, pp. 4-12, 2002.

[14] S. B. M. Tamrin, K. Yokoyama, J. Jalaludin et al., “The association between risk factors and low back pain among commercial vehicle drivers in peninsular Malaysia: a preliminary result," Industrial Health, vol. 45, no. 2, pp. 268-278, 2007.

[15] N. J. Mansfield and J. M. Marshall, "Symptoms of musculoskeletal disorders in stage rally drivers and co-drivers," British Journal of Sports Medicine, vol. 35, no. 5, pp. 314-320, 2001.
[16] J. Abledu, E. Offei, and G. Abledu, "Occupational and personal determinants of musculoskeletal disorders among urban taxi drivers in Ghana," International Scholarly Research Notices, vol. 2014, Article ID 517259, 5 pages, 2014.

[17] M. L. Magnusson, M. H. Pope, D. G. Wilder, B. Areskoug, and A. I. King, "Are occupational drivers at an increased risk for developing musculoskeletal disorders?" Spine, vol. 21, no. 6, pp. 710-717, 1996.

[18] M. Bovenzi, F. Rui, C. Negro et al., "An epidemiological study of low back pain in professional drivers," Journal of Sound and Vibration, vol. 298, no. 3, pp. 514-539, 2006.

[19] W. Albert, D. Everson, M. Rae et al., "Biomechanical and ergonomic assessment of urban transit operators," Work, vol. 47, no. 1, pp. 33-44, 2014.

[20] I. Kuorinka, B. Jonsson, A. Kilbom et al., "Standardised Nordic questionnaires for the analysis of musculoskeletal symptoms," Applied Ergonomics, vol. 18, no. 3, pp. 233-237, 1987.

[21] J. O. Crawford, "The Nordic musculoskeletal questionnaire," Occupational Medicine, vol. 57, no. 4, pp. 300-301, 2007.

[22] C. E. Dickinson, K. Campion, A. F. Foster, S. J. Newman, A. M. T. O'Rourke, and P. G. Thomas, "Questionnaire development: an examination of the Nordic Musculoskeletal questionnaire," Applied Ergonomics, vol. 23, no. 3, pp. 197-201, 1992.

[23] A. O. Akinpelu, O. O. Oyewole, A. C. Odole, and R. O. Olukoya, "Prevalence of musculoskeletal pain and health seeking behaviour among occupational drivers in Ibadan, Nigeria," African Journal of Biomedical Research, vol. 14, no. 2, pp. 89-94, 2011.

[24] A. A. Rufa'i, I. Sa'idu, R. Ahmad et al., "Prevalence and risk factors for low back pain among professional drivers in Kano, Nigeria," Archives of Environmental \& Occupational Health, 2013.

[25] E. M. Langballe, S. T. Innstrand, K. A. Hagtvet, E. Falkum, and O. G. Aasland, "The relationship between burnout and musculoskeletal pain in seven Norwegian occupational groups," Work, vol. 32, no. 2, pp. 179-188, 2009.

[26] V. H. Hildebrandt, P. M. Bongers, J. Dul, F. J. H. van Dijk, and H. C. G. Kemper, "The relationship between leisure time, physical activities and musculoskeletal symptoms and disability in worker populations," International Archives of Occupational and Environmental Health, vol. 73, no. 8, pp. 507-518, 2000.

[27] F. J. Penedo and J. R. Dahn, "Exercise and well-being: a review of mental and physical health benefits associated with physical activity," Current Opinion in Psychiatry, vol. 18, no. 2, pp. 189193, 2005.

[28] T. I. L. Nilsen, A. Holtermann, and P. J. Mork, "Physical exercise, body mass index, and risk of chronic pain in the low back and neck/shoulders: longitudinal data from the nord-trøndelag health study," The American Journal of Epidemiology, vol. 174, no. 3, pp. 267-273, 2011.

[29] T. Morken, T. Riise, B. Moen et al., "Low back pain and widespread pain predict sickness absence among industrial workers," BMC Musculoskeletal Disorders, vol. 4, article 1, pp. $1-8,2003$.

[30] R. D’Onise, E. M. Shanahan, T. Gill, and C. L. Hill, "Does leisure time physical activity protect against shoulder pain at work?" Occupational Medicine, vol. 60, no. 5, pp. 383-388, 2010.

[31] H. Miranda, E. Viikari-Juntura, R. Martikainen, E. Takala, and H. Riihimäki, "Physical exercise and musculoskeletal pain among forest industry workers," Scandinavian Journal of Medicine and Science in Sports, vol. 11, no. 4, pp. 239-246, 2001. 


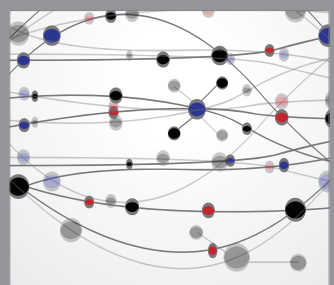

The Scientific World Journal
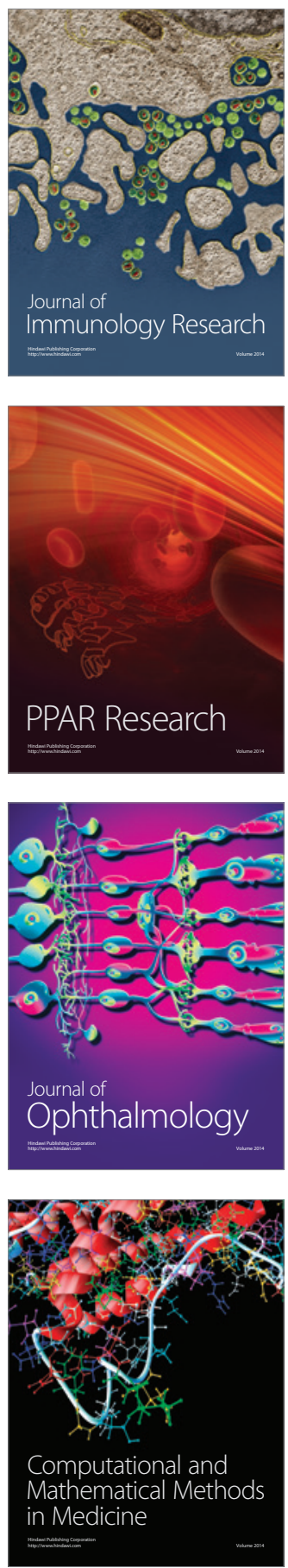

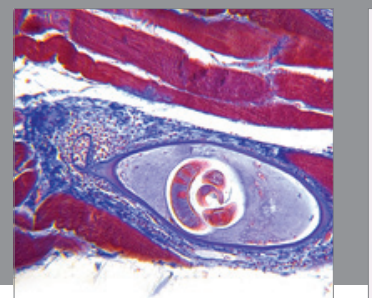

Gastroenterology

Research and Practice
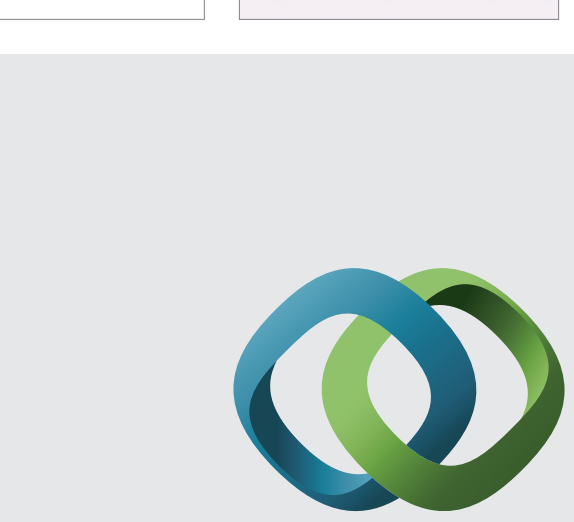

\section{Hindawi}

Submit your manuscripts at

http://www.hindawi.com
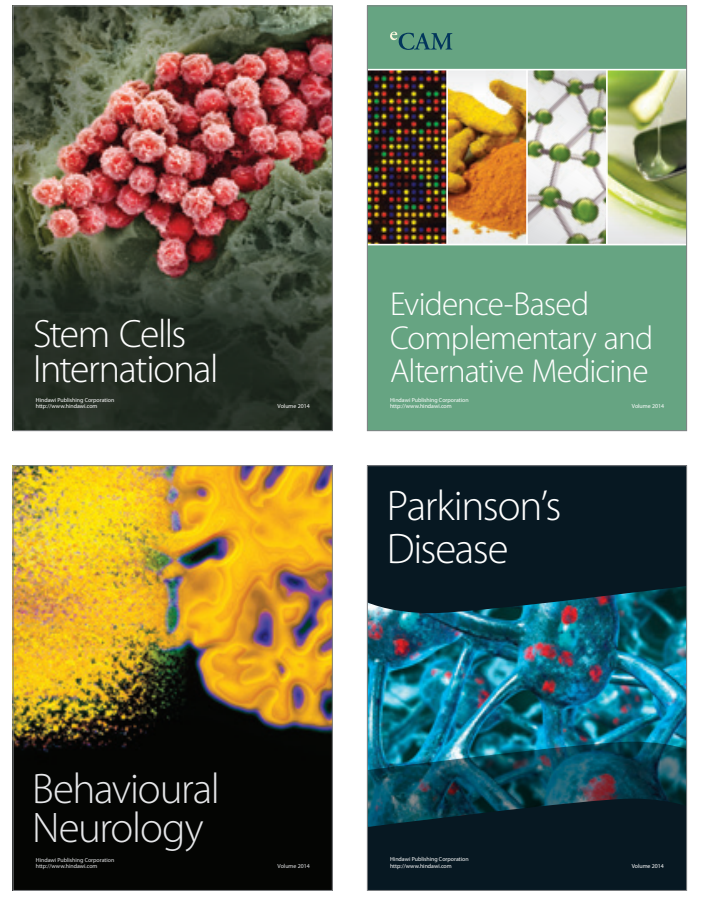
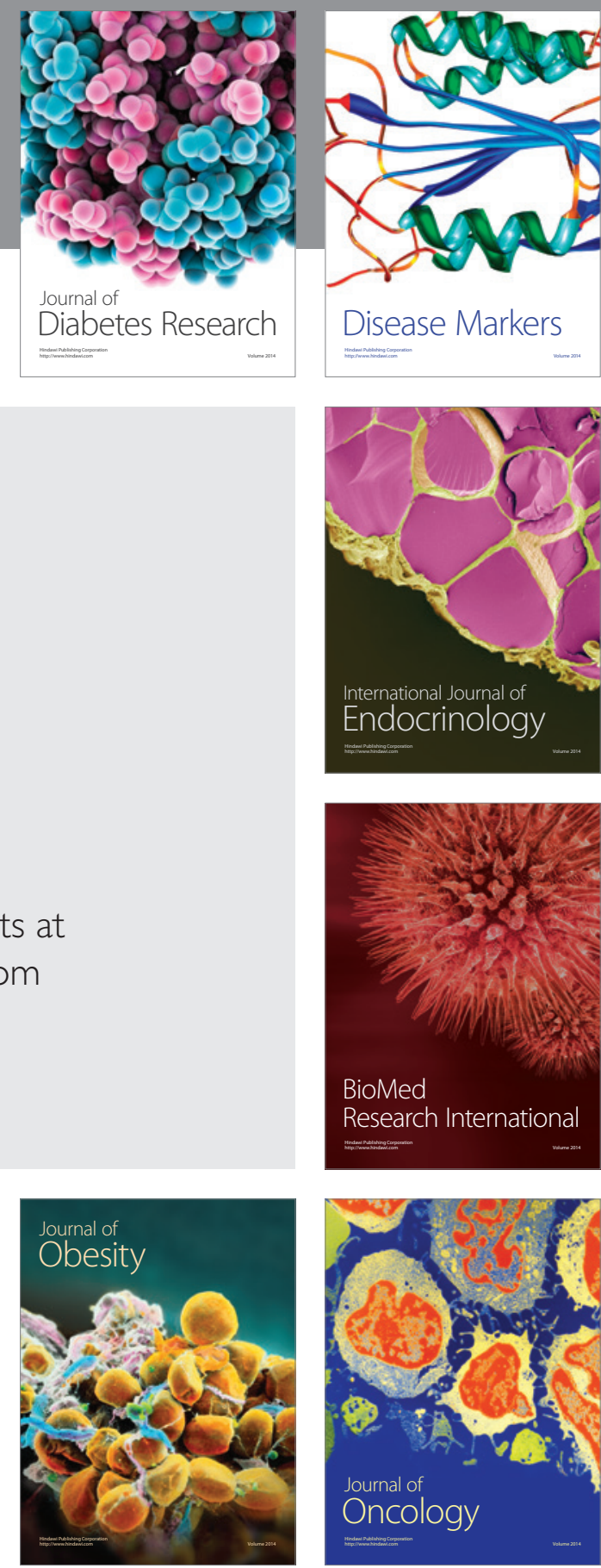

Disease Markers
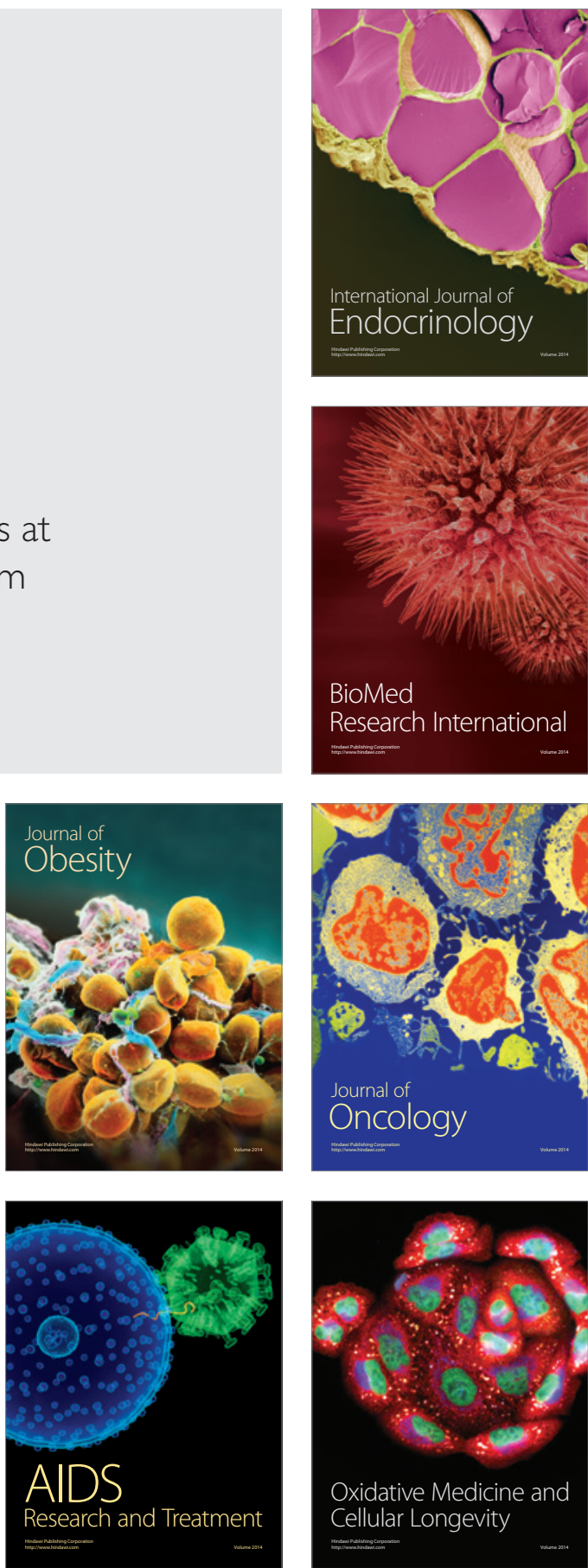